\title{
Compassion Fatigue of Addiction Counselor: Qualitative Study at Rehabilitation Center in Jambi
}

\author{
Siti Raudhoh ${ }^{1}$, Ema Krisnawati ${ }^{2}$ \\ ${ }^{1}$ Department of Psychology, University of Jambi, Indonesia, $\square$ siti.raudhoh@unja.ac.id \\ ${ }^{2}$ Department of Psychology, University of Jambi, Indonesia, $\square$ ema.krisnawati@gmail.com
}

\begin{abstract}
Talking about addiction rehabilitation, addiction counselor became one of the most important roles. Addiction counselors work full time and have big responsibility. The burden and responsibility they got, might lead them to experience a fatigue which is called compassion fatigue. It is exactly dangerous to the performance, personal life, and psychological well-being of the counselors. This research used qualitative research method with thematic analysis approach that aimed to get the description of compassion fatigue of the addiction counselors. The participants of this research were 4 addiction counselors in Jambi. The data collection technique used in this research was in-depth interview. In thematic analysis, the process of coding could produce theme lists and then those themes can be identified at the manifest level. The results showed that there were three components described in compassion fatigue of addiction counselor: symptom, risk factors, and protective factors. The addiction counselor showed some compassion fatigue in order of cognitive, emotional, and behavior domain. Being apathy, as in cognitive domain, was the strongest symptom among the others. Addictive counselor were at risk to suffer from compassion fatigue due to their experience worked as counselor, their experience as an addict-since mostly addictive counselor was an addict once-work stress, maladaptive coping strategies, unhealthy relationship, and their personal problem. Despite of the risks they face, the addictive counselors could still manage them and perform well with regard to the protective factors: adaptive coping strategies, self-development activity, workenvironment, support system, and optimism.
\end{abstract}

Keywords: Addiction Counselor, Compassion Fatigue, Drug Abuse Padang.

\section{Introduction}

Substance abuse is a critical problem in Indonesia across all segments of the population and impacts in some way all members of our society. Based on United Nations World Agency's Report on Drug and Crime (UNODC) in 2012, it is estimated that 149 to 272 million people consumed drugs in 2009 , with the age group 15-64 years old. While in Indonesia, in 2004 the prevalence of drug abusers was $1,5 \%$ and in 2008 it was $1,99 \%$ or around 3,2-3,6 million people, consisting of $26 \%$ tried to use, $27 \%$ regularly used, and $47 \%$ addicts (National Survey of BNN and Pultikes UI, 2008). The significant number of the Indonesian population having substance abuse problems wass indicated by approximately $19,34 \%$ abusing illegal drugs, $7,3 \%$ having problems with drinking, 4,25\% being 
addicted to nicotine and, conservatively, 5\% addicted to prescription medications (BNN and Pultikes UI, 2017).

Substance abuse is defined as the categories classified in the Diagnostic and Statistical Manual IV (DSM-IV) (American Psychiatric Association, 1994) as Substance-Related Disorders and SubstanceInduced Disorders. These disorders include the active use and/or dependency on any mood-altering substance. Substances include alcohol, sedatives, amphetamines, cannabis, cocaine, hallucinogens, inhalants, opioid, caffeine, nicotine, and prescription drugs, as well as legal drugs. Addictive behavior is characterized by preoccupation with the substance or the experience, withdrawal symptoms after not engaging in the substance or experience, increased tolerance for the substance or activity in order to achieve the same effect, and continued use despite negative consequences. An individual with a substance abuse problem is unique in his/her history, pattern of use and abuse, and counseling and related treatment needs.

While many models of causation of substance abuse have been proposed, no clear etiology has been identified. Models emphasize morality or individual conscious choice, biological or disease vulnerability, behavioral learning patterns, cultural-environmental concerns, or biopsychosocial impact. The biopsychosocial model views substance abuse as a complex interaction of all of the other models and endorses multiple strategies for counseling from these models as appropriate. Counselors need to review these models to develop a conceptual position regarding causation upon which he/she can make consistent therapeutic assumptions and decisions to guide counseling practice.

Addiction counselors in Indonesia in general are former drug abusers who have successfully passing through rehab and participate in an addiction training to become a counselor. There is also No. history of drug abuse, but there has been special training to become an addiction counselor. The one of institution $X$ in Jambi has five counselors in which four former drugs users. Since 2016 until August 2018, the Rehabilitation Institute $X$ in Jambi has handled many clients, both who attended inpatient and outpatient programs. The following are data of clients who have participated are:

Table. 1

Client Data in Rehabilitation Institute X Jambi

\begin{tabular}{cccc}
\hline Year & Inpatient & Outpatient & Total \\
\hline 2016 & 21 & 7 & 28 \\
2017 & 19 & 210 & 229 \\
2018 (Jan-August) & 22 & 213 & 235 \\
\hline Total & 62 & 430 & 492 \\
\hline
\end{tabular}

All counselors no matter what their specialty or setting will encounter clients with presenting or related problems of substance abuse. Addiction is severe and chronic, the disorder requires treatment. That treatment is supplied by addiction professionals who are specifically trained to treat addiction. Many times, these professionals have not received any specific training geared toward treating the cooccurrence of addiction and other mental conditions such as trauma (Bride, Hatcher, \& Humble, 2009). Not having specific training regarding how to treat addiction and trauma is an issue because addiction professionals may not be prepared for the possible negative reactions they may experience due to dealing with the traumatic stress of their clients (Knight, 2010).

Addictions counselors work under difficult conditions: funding cuts, restrictions on the delivery of services, changing certification and licensure standards, mandated clients, and clients that need special care (Osborn, 2004). In addition, other situational factors such as low salaries, staff turnover, 
agency upheaval, and limited opportunities for career development create additional burdens (Ogborne, Braun, \& Schmidt, 1998); not to mention the well-known difficulty of working with clients who have high relapse rates (Festinger, Rubenstein, Marlowe, \& Platt, 2001) and high rates of psychiatric comorbidity (McGovern, Xie, Segal, Siembab, \& Drake, 2006).Under those circumstances, burnout has been reported as a prevalent problem among addiction counselors and other providers of mental health care (Balogun, Titiloye, Balogun, Oyeyemi, \& Katz, 2002; Osborn, 2004), especially among those rendering direct services to their recipients (Peterson, 1990).

Compassion fatigue is defined as a combination of physical, emotional and spiritual depletion related to caring for clients with emotionally suffering conditions and experiencing significant physical stress (Lombardo \& Eyre, 2011). Compassion fatigue is an emotional residue exposed from work to face the suffering of others, especially individuals who suffer from traumatic events. Compassion fatigue is an emotional residue exposed from work to face the suffering of others, especially individuals who suffer from traumatic events. Professional who listens to other people's stories of fear, pain and suffering from others will also feel fear and the same pain because they care. Professional are very vulnerable to Compassion Fatigue, including emergency workers, counselors, mental health and medical professionals, pastors, advocates, and human service workers. If an individual experiences as if losing his sense of self, he might be experience compassion fatigue (Thompson, et al, 2014).

The impacts of Compassion Fatigue in someone is characterized by a decrease in performance, error in work and even affect personal life. Compassion fatigue can also have an impact on a person's health loss. A special profession such as a counselor may experience compassion fatigue because he works with clients who suffer and do it every day (Cummins, et al, 2007). This process requires the counselor to consistently gather energy to engage with the emotions of others. The symptoms are avoiding clients, reducing the ability to feel empathy for clients, increased absent in the office, and overall fear of work (Lombardo \& Eyre, 2011). The impact might arise if there is a compassion fatigue can disrupts the performance of the counselor and their personal life. Considering that most of addiction counselors are former abusers, it is not impossible that compassion fatigue can also lead them to relapse and using drugs again.

Based on the explanation above, it is interesting to examine further and in depth description about compassion fatigue among addiction counselors. It is necessary to extract in-depth data about the perceptions and the emotions among addiction counselor when carrying out their roles. Based on these, it interesting to explain the dynamics of the compassion fatigue experienced by addiction counselors $\mathrm{X}$ rehabilitation in Jambi. It also to know the strategy for countering compassion fatigue carried out by addiction counselor in Jambi.

\section{Method}

This study used qualitative methods that aim to understand a phenomenon in a social context naturally to obtain a deeper description and information about compassion fatigue among addiction counselors. Qualitative research also aimed to provide an implicit explanation of the structure, order and the patterns found in a group of participants. The method used in this study is a thematic approach. According to Boyatzis (Braun \& Clarke, 2006) a thematic approach is a method for identifying, analyzing and reporting on themes contained in a phenomenon.

Respondent in this research were selected by purposive sampling technique. In this descriptive qualitative research, four experienced addiction counselors who work with people with drug addicts and trauma were interviewed about their experiences. This research was conducted in Rehabilitation Institute $X$ Jambi. The rehabilitation institution is a private that provides inpatient and outpatient services to various drug abuse cases in Jambi. Respondents in the study disclosed extremely sensitive information about their personal and professional attributes. Therefore, confidentiality of respondents 
was of the most importance to the researchers. To protect the confidentiality of the respondents, further identifying information about the respondent could not be provided. As for the criteria of respondents, were: (1) Addiction counselor at the Rehabilitation Institute X in Jambi; (2) Having a full experience of handling clients; (3) Willing to be an informant.

To obtain data that accordance with the research objectives, data collection techniques used in depth interview methods. Through in-depth interviews, the researchers could explore counselors' personal and emotional experience in handling drug addicts, even their own personal traumatic experience.

The stages of analysis data of this research were : (a) Transcribing data; (b) Generating initial codes; (c) Searching for themes; (d) Reviewing themes; (e) Defining and naming themes; (f) Producing the report. (Braun \& Clarke, 2006).

\section{Results and Discussion}

The participants had a different education and experience background. Two of them had a bachelor degree, while the others went to college but did not finish the study. Three of them had a long experience as an addict before became an addiction counselor. To make it clear, these are the general description about the participants:

Table 2

\section{Description of Participants}

\begin{tabular}{ccccc}
\hline Initial / Sex & Age & Education Backgrouns & $\begin{array}{c}\text { Experience as } \\
\text { Addict }\end{array}$ & $\begin{array}{c}\text { Experience as } \\
\text { Counselor }\end{array}$ \\
\hline P.F / Male & 45 y.o & Senior High School & 7 years & 16 years \\
P.S / Female & 29 y.o & S1 - Psychology & - & 2 years \\
P.H / Male & 30 y.o & S1 - Sports Education & 17 years & 1 year \\
P.W / Male & 28 y.o & Senior High School & 5 years & 3 years \\
\hline
\end{tabular}

The counselors who were an addict, had to attend several programs before becoming an addiction counselor. They had to do a rehab until they had a sober clearance, then attend on-the-job training as a counselor in one of the rehab center with specific program. After that, they had to be a volunteer in rehab center and worked under supervision. P.S had different path to be an addictive counselor. She studied psychology and worked in BNN. Still, she had to do some training about addiction from BNN or Social Ministry.

After some interview sessions with all of the participants, each interview transcripts was coded in some steps. These are the summary of the coded data:

Table 3.

Early step of thematic analysis

\begin{tabular}{|c|c|c|c|c|c|c|}
\hline \multirow{2}{*}{ Domain } & \multirow{2}{*}{ Themes } & \multirow{2}{*}{ Subthemes } & \multicolumn{4}{|c|}{ Participants } \\
\hline & & & P.F & P.W & P.H & P.S \\
\hline \multirow{4}{*}{ SYMPTOM } & \multirow{4}{*}{ A. Cognitive } & 1. Apathy & $\sqrt{ }$ & $\sqrt{ }$ & & $\sqrt{ }$ \\
\hline & & 2. Low self esteem & $\sqrt{ }$ & & $\sqrt{ }$ & $\sqrt{ }$ \\
\hline & & 3. Lack of concentration & $\sqrt{ }$ & & & $\sqrt{ }$ \\
\hline & & 4. Negativistic & $\sqrt{ }$ & & & $\sqrt{ }$ \\
\hline
\end{tabular}




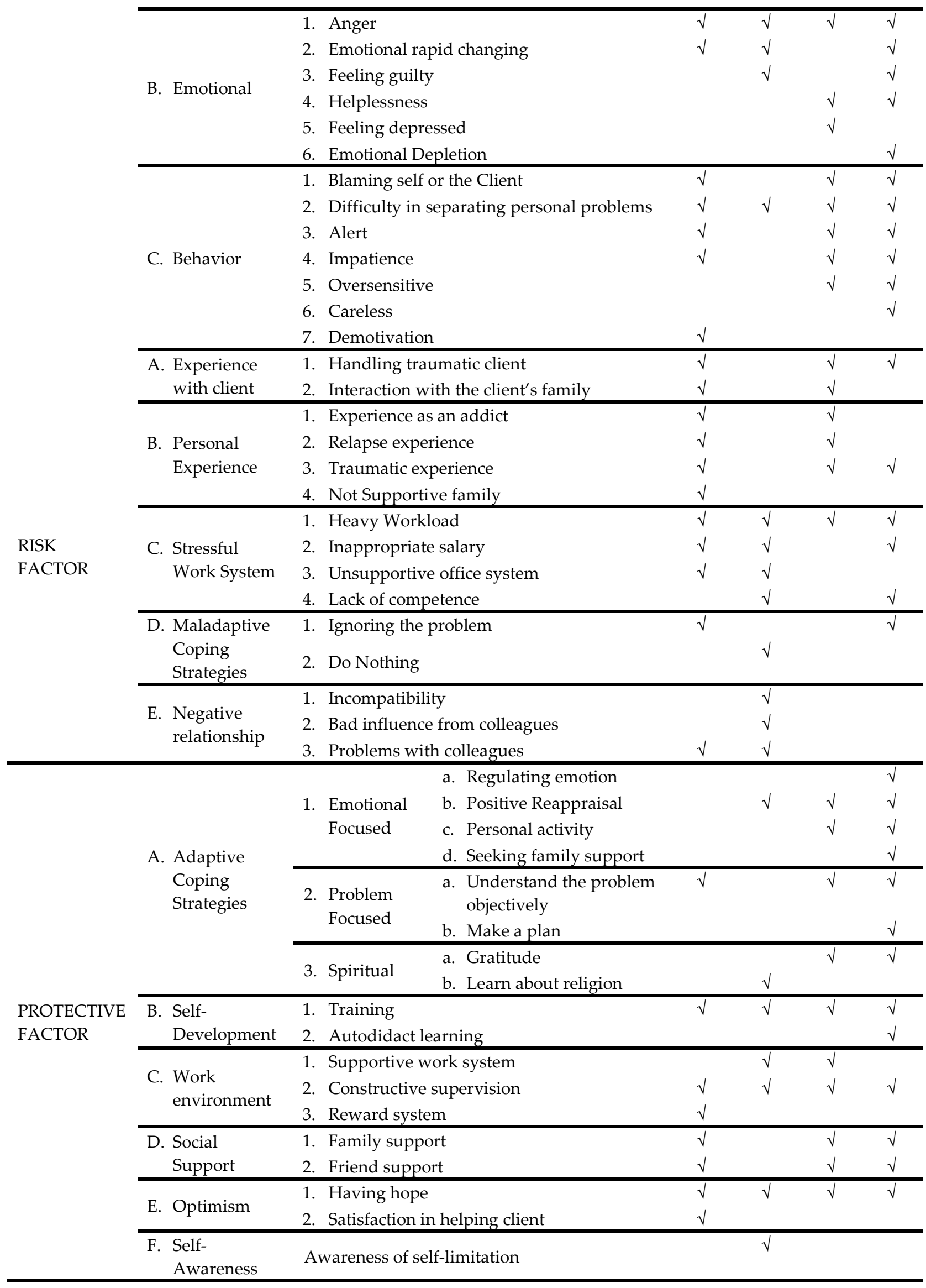


This research explored three domains in compassion fatigue: symptom, risk factor, and protective factor. All participants had been exposed to compassion fatigue while handling the clients. They had different symptom in all area, dominantly in behavioral symptom. P.S had almost all of the symptom except feeling depressed and demotivation, while P.W had the least symptom and most of it were emotional symptoms. P.W was the only participant that had not handled traumatic client yet. Compassion fatigue is specifically defined as a state of tension, stress, and preoccupation felt by counselor in helping traumatized client by re-experiencing the traumatic events of the client (Figley, 2002). According to that statement, it was not accurate to say that P.W exposed to compassion fatigue. He indeed had similar symptom to compassion fatigue, but it could be any other condition except compassion fatigue.

Compassion fatigue has similar construct with concept of burn out. Burnout is defined as, "a psychological syndrome that develops in response to chronic emotional and interpersonal stress" (DePippo, 2015). The most important difference between compassion fatigue and burnout was whether the counselor exposed to traumatized client or not. Burnout is a state of emotional and physical exhaustion caused by excessive and prolonged stress (Circenisa \& Millere, 2011). So, P.W might suffer more from burnout than compassion fatigue.

Some addiction counselors were an addict before, just like those participants. This became a unique challenge to them since they similar experience to their client. On the other hand, it made them vulnerable to run into compassion fatigue, because of the traumatic event as an addict. It was like the client's traumatic experience channeling to the counselor's personal traumatic experience. So, not only traumatized client, but also counselors' personal traumatic event could be the risk factor to compassion fatigue (DePippo, 2015).

According to the participants, they still counseled their client despite of all the symptoms. Sometimes they could build a good relationship and fully help the client, and other time they did not. CF symptom shown by the participant were influenced by the risk factors. Risk factor is anything-including emotional conditions--that are the trigger of negative behavior or activity (DePippo, 2015) . According to the participants, they still counseled their client despite of all the CF symptoms. Sometimes they could build a good relationship and fully help the client, and other time they did not. When they succeed in conquering the CF symptoms, protective factors made them be able to manage it. Protective Factor is a characteristic found in individuals and also outside itself and capable to reducing or fighting the behavior problem (DePippo, 2015).

In the early thematic analysis, there were five risk factors of compassion fatigue to the addiction counselor: (1) experience with the client, specially traumatized client, (2) personal experience, including traumatic experiences, (3) stressful work system, (4) maladaptive coping strategies, (5) negative relationship. Stressful work system and negative relationship were things that could lead the counselor into burnout, so those factors included as burnout. In the final analysis, CF risk factors were divided into four categories: (1) experience with the client, (2) personal experience, (3) maladaptive coping strategies, and (4) burnout.

In the beginning, there were six protective factors: (1) adaptive coping strategies, (2) selfdevelopment, (3) work environment, (4) social support, (5) optimism, and (6) self-awareness. Positive work environment and social support, in the contrary to risk factor, could lead the counselors to have more healthy conditions. So, in the final analysis, there were only four protective factors: (1) adaptive coping strategies, (2) self-development, (3) optimism, and (4) self-awareness. Coping played an important role that could lead the counselor into compassion fatigue or not. Adaptive coping would make the counselor be able to handle their emotional and personal distress so they still could perform in their high functioning work. In the contrary, maladaptive coping strategies would make the counselor stay in the bad situation that lead to compassion fatigue. 
To make it clear, the cycle of compassion fatigue is explained in Figure.1

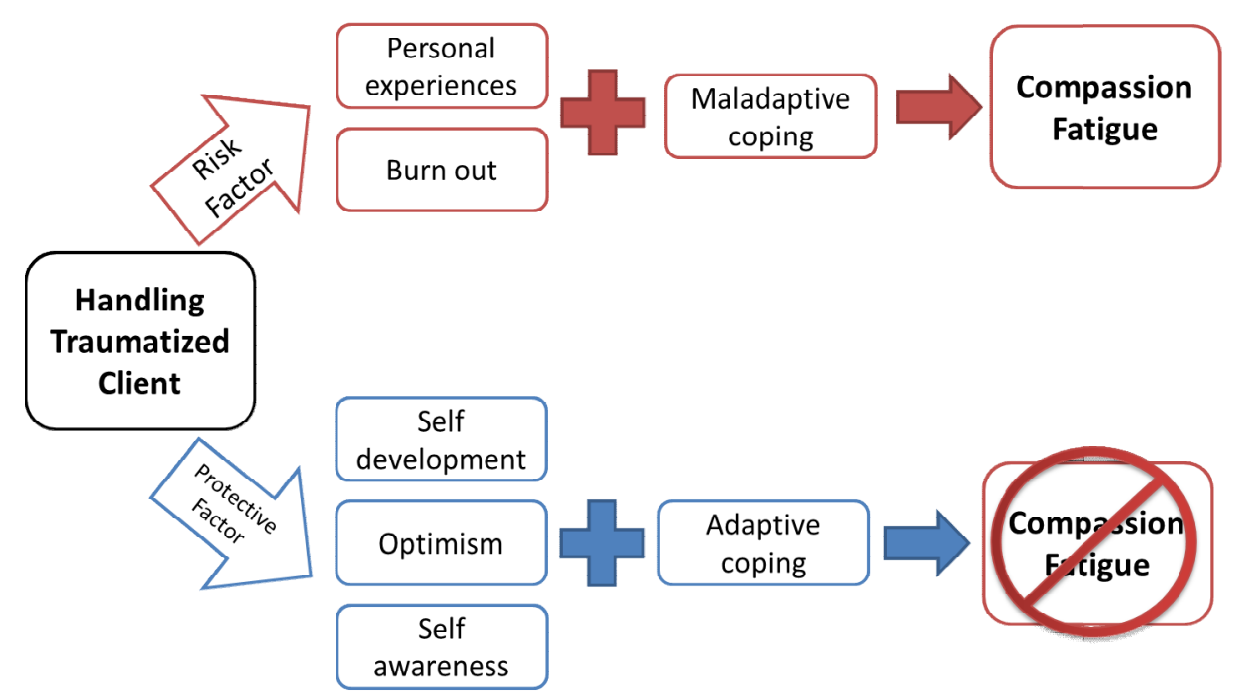

Figure 1. Risk factor and Protective factor of compassion fatigue adapted from Middleton and developed based on research result (Cocker, 2016)

When the counselor handling traumatized client, it might lead them to compassion fatigue if they had personal traumatic experience, burnout, and could not perform any adaptive coping strategies. But, if they had protective factors more than risk factors and they can perform adaptive coping, they might not have compassion fatigue. This research explored the experiences of four addictive counselors in on rehabilitation center. The concept above need to be proved in bigger subject so it can be generalized in bigger population. Comparing counselor with and without addiction experience would be one of the topics for further research.

\section{Conclusions}

Compassion fatigue could be face by any addictive counselor. The symptoms would be shown in cognitive, emotional, and behavioral domain. Every counselor would show different symptoms. Addictive counselors suffered from compassion fatigue due to the combination of risk factors and protective factors. The risk factors were: 1) experience with the client, (2) personal experience, (3) maladaptive coping strategies, and (4) burn out. The protective factors were: 1) adaptive coping strategies, (2) self-development, (3) optimism, and (4) self-awareness. The result of this research need to be presented to stakeholders of Rehabilitation Institute $X$ in Jambi so they could make a policy to reduce the compassion fatigue among the addictive counselor in there.

\section{Acknowledgments}

This research would not have been possible without the financial support of Faculty Medicine and Health Science, University of Jambi. We were grateful to all of those with whom we have had the pleasure to work during this and other related projects. Each of members of our research assistance has provided us extensive personal and work professional. We would especially like to thank our participants, also the chairman of Rehabilitation Institute $\mathrm{X}$ in Jambi, for the kindness and cooperation. 


\section{References}

Balogun, J.A. Titiloye, V, Balogun, A. Oyeyemi, A. \& Katz, J. (2002). Prevalence and Determinants of Burnout Among Physical and Ocuupational Therapist. Journal of Allied Health (31), 131-139

Braun, V., Clarke, V., Clark, V., \& Clarke, V. (2006). Using thematic analysis in Psychology. Qualitative Research in Psychology, 3(2), 77-101. https://doi.org/10.1191/1478088706qp063oa

Bride, B. E., Hatcher, S. S., \& Humble, M. N. (2009). Trauma training, trauma practices, and secondary traumatic stress among substance abuse counselors. Traumatology, 15(2), 96-105. https://doi.org/10.1177/1534765609336362

BNN \& Pusat Penelitian Kesehatan Universitas Indonesia. 2017. Laporan Survei Penyalahgunaan Narkoba di Indonesia. Jakarta: Universitas Indonesia

Cocker, F., \& Joss, N. (2016). Compassion fatigue among healthcare, emergency and community service workers: A systematic review. International Journal of Environmental Research and Public Health, 13(6), 1-18. http://doi.org/10.3390/ijerph13060618

Creswell, J. W. (2014). Penelitian kualitatif dan desain riset (A. Lazuardi, Trans.), Yogykakarta: Pustaka pelajar. (Naskah asli diterbitkan tahun 2013)

Cummins, P. N., Massey, L., \& Jones , A. (2007). Keeping ourselves well: Strategies for promoting and maintaining counselor wellness. The Journal of Humanistic Counseling, Education and Development (46), 35-49. Doi: 10.1002/j.2161-1939.2007.tb00024.x

DePippo, A. G. (2015). Compassion Fatigue and Self-Care Strategies among Addiction Professionals: A Qualitative Study. ProQuest Dissertations and Theses, (January), 170. Retrieved from http://ezproxy.lib.ryerson.ca/login?url=http://search.proquest.com/docview/1696782198?account $\mathrm{id}=13631 \% 5 \mathrm{Cnhttp} / / /$ sfx.scholarsportal.info/ryerson??url ver=Z39.88-

2004\&rft val fmt=info:ofi/fmt:kev:mtx:dissertation\&genre=dissertations+\&+theses\&sid=ProQ:Pr oQue

Festinger, D.S. Rubenstein, D. F. Marlowe, D.B \& Platt, J. J. (2001). Relapse: Contributing Factors, Causative Models and Empirical Considerations. New Haven, CT, US: Yale University Press.

Figley, C. R. (2002). Compassion fatigue: Psychotherapists' chronic lack of self care. Journal of Clinical Psychology, 58(11), 1433-1441. https://doi.org/10.1002/jclp.10090

Knight, C. (2010). Indirect trauma in the field practicum: Secondary traumatic stress, vicarious trauma, and compassion fatigue among social work students and their instructors. Journal of Baccalaureate Social Work, 15 (1), 31-52. https://doi.org/10.5555/basw.15.1.1568283x21397357

Lombardo, B., \& Eyre, C.(2011). Compassion Fatigue: A Nurse's Primer. The Online Journal of Issues in Nursing (16). Doi : 10.3912/OJIN.Vol16No01mAN03.

Mc Govern, M. P. Xie, H. Y. Segal, S. R. Siembab, L \& Drake, R.E. 2006. Addiction Treatment Services and Co-occurring disorders: Prevalence Estimates, Treatment Practices, and Barriers. Journal of Substance Abuse Treatment (31), 267-275. Doi: 10.1016/j.sat.2006.05.003 
Ogborne, A.C. Braun, K. \& Schmidt, G. (1998). Working in Addictions Treatment Services: Some views of a sample of Service Providers in Ontario. Substance Use \& Misuse (33), 2425-2240.

Osborn, C.J. (2004). Seven Salutary Suggestions for Counselor Stamina. Journal of Counseling $\mathcal{E}$ Development (82), 319-328. http://doi.org/10.1002/j.1556-6678.2004.tb00317.x

Peterson, K. H. (1990). Occupational Stress and Burnout Among Addiction Counselors. Dissertation Abstracts International (50), 2781-2782

Thompson, I. A., Amatea, E.S., \& Thompson, E. S. (2014). Personal and Contextual Predictors of Mental Health Counselor's Compassion Fatigue and Burnout. Journal of Mental Health Counseling (36), 58-77 